\title{
Downregulation of peroxiredoxin II suppresses the proliferation and metastasis of gastric cancer cells
}

\author{
LINJUN NIU*, ANG LIU* ${ }^{*}$ WEI XU, LIANG YANG, WUGANG ZHU and YUMING GU \\ Department of Interventional Radiology, Affiliated Hospital of Xuzhou Medical University, \\ Xuzhou, Jiangsu 221002, P.R. China
}

Received November 2, 2017; Accepted April 18, 2018

DOI: $10.3892 / \mathrm{ol} .2018 .9208$

\begin{abstract}
Peroxiredoxin (Prx) II is an imperative member of the superfamily of peroxidases. It serves an essential role in scavenging organic hydroperoxide and $\mathrm{H}_{2} \mathrm{O}_{2}$. It is involved in the development of various malignant tumors. In order to investigate the significance of Prx II expressions level in gastric cancer (GC), downregulation of Prx II was performed to investigate its role in the proliferation and migration of gastric adenocarcinoma cells. In GC cells and 45 GC specimens, the mRNA and protein expression levels of Prx II were determined using reverse transcription-quantitative polymerase chain reaction (RT-qPCR) and western blot analysis, respectively. The Prx II expression profile in another 116 GC specimens was also detected with immunohistochemistry (IHC). The changes in the proliferation and migration of MKN45 and MGC-803 cells folllowing transfection with small interfering RNA (siRNA) were detected by cell counting kit (CCK)-8, western blot analysis, and Transwell migration and invasion assays. The results revealed that the expression of Prx II in GC tissues and GC cells were significantly upregulated compared with the normal control. There was a significant association between the expression level of Prx II and various factors, including tumor size, histological differentiation, the depth of invasion, the stage of tumor-node-metastasis (TNM) and lymph node metastasis in GC $(\mathrm{P}<0.05)$. Survival in patients with higher Prx II expression was significantly decreased compared with those with lower Prx II expression $(\mathrm{P}<0.01)$. Prx II, depth of invasion, lymph node metastasis and distant metastasis were identified as independent prognosis factors of GC $(\mathrm{P}<0.05)$. Knockdown of Prx II significantly suppressed the proliferation and the migration of GC cells. These experiments revealed that
\end{abstract}

Correspondence to: Professor Yuming Gu, Department of Interventional Radiology, Affiliated Hospital of Xuzhou Medical University, 99 West Huaihai Road, Xuzhou, Jiangsu 221002, P.R. China

E-mail: guyuming_2006@163.com

*Contributed equally

Key words: peroxiredoxin II, gastric cancer, proliferation, invasion, migration
Prx II promotes the development of GC, affecting the survival of patients with GC.

\section{Introduction}

Gastric cancer (GC) is the second highest cause of global disease-associated mortality globally (1). With the progression in surgery resection and chemotherapy, the clinical result of GC has been enhanced gradually. However, the 5-year survival rate remains $20-30 \%$ (2). It is assumed that poor prognosis is associated with the multifaceted and malignant characteristics of GC $(3,4)$. Previous studies have reported that various factors are associated with the pathogenesis of GC, including bad eating habits, gastric ulcers and Helicobacter pylori infection (5-7). However, the molecular mechanisms of GC are not fully understood, and include a variety of tumor-associated factors and genetic modifications of tumor suppressor factors. Molecular studies investigating alterations in single genes have provided evidence that GC progresses via different genetic pathways (8-10). Therefore, the present study aimed to decipher the molecular mechanism of GC, in order to establish deeper understanding of GC and identify possible treatments for patients with GC.

Peroxiredoxins (Prxs) exist in prokaryotes and eukaryotes, and regulate the redox reaction in the body. Researchers have demonstrated that Prxs are highly expressed in different cancer tissues and immortalized cell lines (including lung, renal and hepatocellular carcinoma cell lines), and promote the progression of cancer $(11,12)$. High expression of Prxs is associated with the protection of tumors and malignancy, which has been associated with resistance of cell lines against certain chemotherapies and radiotherapies $(13,14)$. As one of the six components of the peroxiredoxin family, Prx II serves essential roles in different tumors. Lehtonen et al (15) reported that the expression of Prx II was upregulated in bosom carcinoma. Soini et al (16) demonstrated that the expression of Prx II was associated with the development of renal cancer. However, the effect of Prx II expression on GC growth remains unclear. In the present study, the association between Prx II expression and GC was investigated using GC tissues and cells.

Epithelial-mesenchymal-transition (EMT) involves changes in epithelial cells into ectomesenchymal cells under particular conditions. It is involved in regulating tissue development and repairing tissue injuries, and is associated with the invasion and metastasis of tumors (17). The proteins associated with EMT, 
including E-cadherin and $\mathrm{N}$-cadherin, serve an important role in GC $(18,19)$. Matrix metalloproteinase (MMP)-2 and MMP-9 are also associated with the metastasis of GC. The current analysis aimed to investigate the effect of Prx II on GC cell migration and proliferation by detecting the changes in MMP-2, MMP-9, E-cadherin and N-cadherin expression in GC following the downregulation of PrxII. It was revealed that Prx II promoted the proliferation and migration of GC cells. Thus, Prx II may be a promising target for treatment in GC.

\section{Materials and methods}

Patients and samples. Between January 2009 and December 2010, a total of 116 paraffin-embedded sections were collected from patients who underwent gastrectomy at the Affiliated Hospital of Xuzhou Medical College (Xuzhou, China). These samples were made into a tissue microarray, and the expression of Prx II was investigated using immunohistochemistry (IHC). The hospital routinely detects the expression of Ki-67 in GC tissue following surgery. The positive expression rate of $\mathrm{Ki}-67$ was $62.1 \%(72 / 116)$ in GC tissues, which indicated the proliferation of GC with higher Ki-67 expression was significantly increased compared with those with lower Ki-67 expression. Additionally, 45 cases of patients with primary gastric carcinoma receiving gastrectomy at the Affiliated Hospital of Xuzhou Medical University between September 2015 and January 2016 were included. The 45 fresh frozen GC tissues and matched adjacent non-cancerous tissues were utilized for western blot analysis or reverse transcription-quantitative polymerase chain reaction (RT-qPCR) investigation. The positive expression rate of Ki-67 was $73.3 \%$ (33/45) in the GC tissues. None of the patients had been treated with chemotherapy or radiotherapy prior to the surgery, and no other malignant tumors were identified. The patient's overall survival time and disease-free survival time were statistically analyzed. Overall survival was defined as the duration from the time of diagnosis to the time of mortality from any cause. Disease-free survival was defined as the duration from the time of diagnosis to the time of mortality from disease progression. The present study was approved by the Ethics Review Board of the Affiliated Hospital of Xuzhou Medical College. All patients provided written informed consent.

Cell culture. The human GC cell lines MKN-45, MGC-803 and typical gastric cells (GES-1) were purchased from the Cell Bank of Chinese Academy of Sciences (Shanghai, China). The cells were cultured in the Dulbecco's modified Eagle medium (DMEM) (Gibco; Thermo Fisher Scientific, Inc., Waltham, MA, USA) with $100 \mathrm{U} / \mathrm{ml}$ penicillin and $100 \mu \mathrm{g} / \mathrm{ml}$ streptomycin, supplemented with $10 \%$ heat-inactivated fetal bovine serum (FBS; Beyotime Institute of Biotechnology, Nanjing, China). These cells were cultured at $37^{\circ} \mathrm{C}$ in a humidified environment with $5 \% \mathrm{CO}_{2}$

RNA interference and transfection. When cells had achieved $70 \%$ confluence, small interfering (si)RNA sequences for Prx II and a scrambled nonspecific sequence (Shanghai GenePharma Co., Ltd., Shanghai, China) were transfected using Silentfect reagent (Invitrogen; Thermo Fisher Scientific, Inc.) according to the manufacturer's protocol. The medium was replaced after
6-8 $\mathrm{h}$ of transfection in order to prevent toxicity. The cells were then transfected for $48 \mathrm{~h}$ prior to use in subsequent experiments. The Prx II siRNA sequences were as follows: Forward primer, 5'-CCUAGA AGCUGA AUAGUGA-3'; reverse primer, 5'-UCACUAUUCAGCUUCUAGG-3'. The scrambled siRNA sequences were as follows: Forward primer, 5'-UUC UCCGAACGUGUCACGU-3'; reverse primer, 5'-ACGUGA CACGUUCGGAGAA-3'.

Western blot analysis. Cells or 60-80 mg tissues were lysed using radio immunoprecipitation assay lysis buffer (Beyotime Institute of Biotechnology), and the concentration of protein was determined using a bicinchoninic acid assay (Beyotime Institute of Biotechnology). The protein was denatured by boiling at $100^{\circ} \mathrm{C}$ for $5 \mathrm{~min}$. A total of $25 \mu \mathrm{g}$ protein of each sample was subjected to SDS-PAGE (8 and 10\% gels) and transferred to polyvinylidene fluoride membranes. The membranes were blocked with $5 \%$ skimmed milk and Tris-buffered saline with Tween 20 at $37^{\circ} \mathrm{C}$ for $1.5 \mathrm{~h}$ and were incubated with primary antibodies against Prx II (dilution, 1:3,000; cat no. ab15572; ABclonal Biotech Co., Ltd., Woburn, MA, USA), E-cadherin, $\mathrm{N}$-cadherin, MMP-2, MMP-9 or $\beta$-actin (dilution, 1:5,000; cat nos. 9961S, 5296S, 4061S, 3852S and 8457S, respectively; Cell Signaling Technology, Inc., Danvers, MA, USA) at $4^{\circ} \mathrm{C}$ for $12 \mathrm{~h}$, followed by incubation with monoclonal goat anti-mouse or anti-rabbit fluorophore-conjugated secondary antibodies (dilution, 1:10,000; cat no. RK-611-130-002; LI-COR Biotechnology, Lincoln, NE, USA) at $37^{\circ} \mathrm{C}$ for $1.5 \mathrm{~h}$. Enhanced chemiluminescence detection reagent (Tanon Science and Technology Co., Ltd., Shanghai, China) was used to visualize the bands with an Odyssey ${ }^{\circledR}$ CLx Infrared Imaging system (cat no. 9140-00; LI-COR Biotechnology).

Immunohistochemical staining. Immunostaining was performed on tissue microarray samples. The microarray samples were processed in accordance with a previously described method (20). The microarrays were incubated with rabbit monoclonal antibody against human Prx II (1:200; cat no. ab15572; ABclonal Biotech Co., Ltd.) for $12 \mathrm{~h}$ at $4^{\circ} \mathrm{C}$, and biotinylated goat anti-rabbit serum $\mathrm{IgG}$ was utilized as an secondary antibody (dilution, 1:5,000; cat no. RK-611-130-002; LI-COR Biotechnology) at $37^{\circ} \mathrm{C}$ for $0.5 \mathrm{~h}$. Following washing

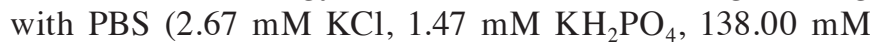
$\mathrm{NaCl}$ and $8.10 \mathrm{Mm} \mathrm{Na} \mathrm{HPO}_{4}$ ), the slices were incubated with diaminobenzidine substrate at $37^{\circ} \mathrm{C}$ for $2 \mathrm{~min}$. The immunoreactivity of Prx II was rated as 0, negative (0-10\%); 1 , weak $(11-25 \%) ; 2$, moderate $(26-50 \%)$ or 3 , strong $(>50 \%)$ according to the staining area of positive tumor cells as previously described (20). Weakness to moderate signals $(<50 \%)$ of GC cells were considered as exhibiting a low expression of Prx II. In contrast, strong staining of GC cells (>50\%) was considered to exhibit a high expression of Prx II. Positive and negative biopsy samples were used as the positive and negative control. Sections were observed at magnification, $\mathrm{x} 400$ with a light BHS/System Living microscope (Olympus Corporation, Tokyo, Japan) and the outcomes were categorized according to the brown granules in the cytoplasm.

$R T-q P C R$. According to the manufacturer's protocol, RNA was isolated from tissue (Invitrogen; Thermo Fisher Scientific, Inc.). 

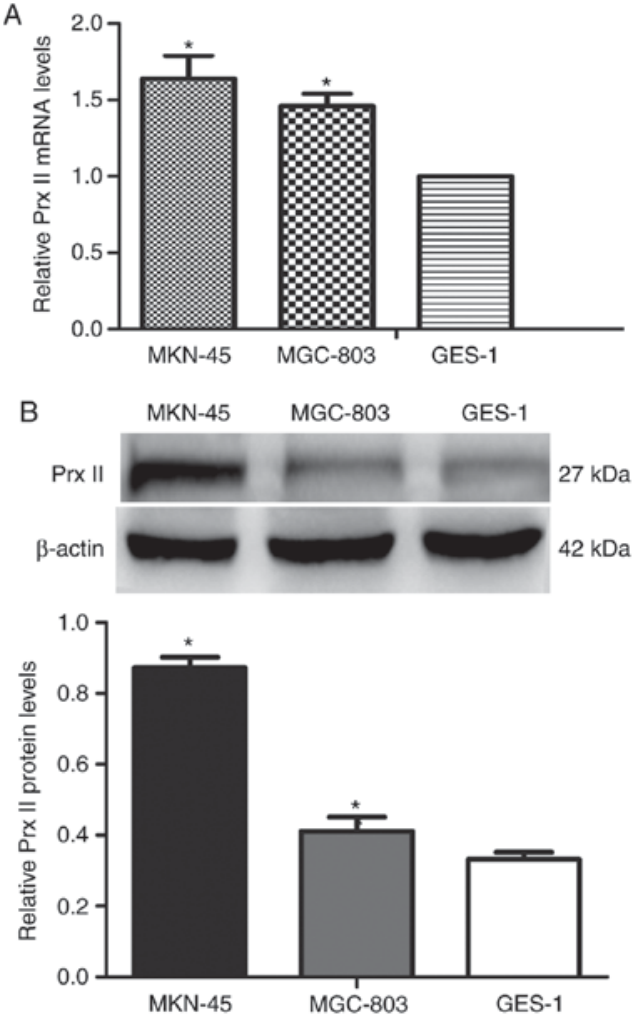

Figure 1. Prx II is upregulated in GC cell lines. (A) Reverse transcriptionquantitative polymerase chain reaction and (B) western blotting was used to in GC cell lines. The mRNA and protein expression of Prx II were analyzed in normal cells of the stomach (GES-1) and GC cell lines, MGC-803 and MKN-45. Each bar represents three independent experiments presented as the mean \pm standard deviation; error bars represent the standard deviation. ${ }^{*} \mathrm{P}<0.05$ vs. GSE-1. Prx, peroxiredoxin; GC, gastric cancer.

The content of total RNA was measured and calculated using the A260/A280 ratio. Then, $3 \mu \mathrm{g}$ RNA was used for reverse transcription using the TIANScript First Strand cDNA Synthesis kit (BioTeke Corporation, Beijing, China) according to the manufacturer's protocol. The cDNA was amplified using PCR using an ABI 7500 PCR system (Applied Biosystems; Thermo Fisher Scientific, Inc.) with SYBR ${ }^{\circledR}$ Premix Ex Taq ${ }^{\mathrm{TM}}$ (Takara Bio Inc., Japan). The $20 \mu 1$ reaction comprised $10 \mu 1$ SYBR Green premix and $10 \mu 1$ primer mix (including cDNA). The thermocycling conditions were as follows: $95^{\circ} \mathrm{C}$ for $30 \mathrm{sec}$ (1 cycle); $95^{\circ} \mathrm{C}$ for $5 \mathrm{sec}$ and $64^{\circ} \mathrm{C}$ for $34 \mathrm{sec}\left(40\right.$ cycles); $95^{\circ} \mathrm{C}$ for $15 \mathrm{sec}$ and $60^{\circ} \mathrm{C}$ for $60 \mathrm{sec}$, and $95^{\circ} \mathrm{C}$ for $15 \mathrm{sec}(1 \mathrm{cycle})$. The expression level of Prx II was normalized to GAPDH and calculated using the $2^{-\triangle \Delta C q}$ method (21). The primers used were as follows: Prx II forward, 5'-GTGTCCTTCGCCAGA TCACT-3' and reverse, 5'-AAACTTCCCCATGCTCGTCT-3'; GAPDH forward, 5'-GCAAATTCCATGGCACCGT-3' and reverse, 5'-TCGCCCCACTTGATTTTGG-3'.

Cell proliferation assay. Cell Counting kit-8 (CCK-8) reagent was used to examine cell proliferation (Dojindo Molecular Technologies, Inc., Kumamoto, Japan). MGC-803 and MKN-45 cells were incubated in 96 -well plates $\left(3 \times 10^{3}\right.$ cells/well) (Corning Incorporated, Corning, NY, USA) in $100 \mu \mathrm{l}$ DMEM. Following incubation for 24, 48, 72 and $96 \mathrm{~h}$, the supernatant was extracted, and $100 \mu \mathrm{l}$ serum-free DMEM and $10 \mu \mathrm{l} \mathrm{CCK}-8$ solution was added to each well, followed by further incubation for $2 \mathrm{~h}$ at $37^{\circ} \mathrm{C}$. SiRNA with an unspecific scrambled sequence was used as a negative control (NC). SiRNA with a positive sequence was used as a positive control (siRNA). The positive sequence for Prx II was: Sense, 5'-CCUAGAAGCUGAAUA GUGA-3' and antisense, 5'-UCACUAUUCAGCUUCUAG G-3'. The negative sequence for Prx II was: Sense, 5'-UUC UCCGAACGUGUCACGU-3' and antisense, 5'-ACGUGA CACGUUCGGAGAA-3'. No added sequence was used as a blank control (Blank). The absorbance at $450 \mathrm{~nm}$ was recorded with an ELX-800 Absorbance reader (BioTek Instruments, Inc., Winooski, VT, USA). Each experiment was repeated not $\geq 3$ times under similar conditions.

Cell migration and invasion assay. Transwell chambers (EMD Millipore, Billerica, MA, USA) with an $8-\mu \mathrm{m}$ pore polycarbonate membrane filter was covered with $60 \mu \mathrm{l} /$ well Matrigel (BD Biosciences, San Jose, CA, USA) for the invasion assay or without Matrigel for a migration assay and inserted in a 24-well cultured plate. A total of $600 \mu \mathrm{l}$ DMEM with $10 \%$ fetal bovine serum was placed in the bottom compartment of the chamber, $200 \mu \mathrm{l}$ of serum-free medium containing $\sim 2 \times 10^{4}$ cells were added into the upper compartment of the chamber. The chamber was incubated at $37^{\circ} \mathrm{C}$ in a humidified chamber in an atmosphere of $5 \% \mathrm{CO}_{2}$ for $12 \mathrm{~h}$ (migration assay) or $24 \mathrm{~h}$ (invasion assay). The evaluation of migration and invasion was performed at different times as invasion experiments require gel plating, thus cells need to be cultured for longer to pass through the membrane.

Following incubation, the Transwell chambers were removed. The non-invasive cells on the upper side of the chamber were collected with a cotton swab. Cells that migrated into the pores of the inserted filter were fixed with $95 \%$ methanol at $37^{\circ} \mathrm{C}$ for $30 \mathrm{~min}$ and stained with $0.5 \%$ crystal violet at $37^{\circ} \mathrm{C}$ for $30 \mathrm{~min}$. Images of the cells in the lower chamber were captured using a fluorescence microscope (Ti-U; Nikon Corporation, Tokyo, Japan) equipped with NIS-Elements F3.2. software (Nikon Corporation) at magnification, $\mathrm{x} 200$. The number of cells was recorded by randomly selecting five visual fields in the Transwell chamber.

Statistical analysis. All data were analyzed by using SPSS software version 16.0 (SPSS, Inc., Chicago, IL, USA) and GraphPad Prism 5.0 (GraphPad, San Diego, CA, USA). Quantitative data is presented as the mean \pm standard deviation. The Student's t-test was used to analyze data between two groups, and one-way analysis of variance with post hoc contrast Student-Newman-Keuls test was applied for multigroup comparison. $\chi^{2}$ was applied for the numeration data. Survival data was examined by the Kaplan-Meier method, and the contrast among the groups were analyzed by utilizing the log-rank test. Independent prognostic indicators in the multivariate investigation were evaluated by utilizing the Cox's proportional hazard model. $\mathrm{P}<0.05$ is considered to indicate significant differences in statistics.

\section{Results}

Upregulated Prx II expression in GC cells. With the use of RT-qPCR, the mRNA expression level of Prx II in GC cell lines (MGC-803 and MKN-45) were identified to be significantly higher compared with that in normal cells of 
the stomach (GES-1) (P<0.05; Fig. 1A). For further confirmation, the protein expression of Prx II in cells were examined (MGC-803, MKN-45, GES-1) by western blotting, which demonstrated consistent results $(\mathrm{P}<0.05$; Fig. 1B). Compared with GES-1 cells, the mRNA and protein expression levels of Prx II exhibited no statistically significant difference between different GC cell lines (MGC-803, MKN-45; P>0.05).

Upregulated Prx II expression in GC tissues. First, the mRNA expression level of Prx II in 45 paired GC and adjacent non-cancerous gastric tissues was analyzed with RT-qPCR. The mean mRNA level of Prx II in the GC tissues (1.38 \pm 0.22$)$ was significantly higher compared with that in adjacent tissues $(1.00 \pm 0.00$; $\mathrm{P}<0.01$; Fig. $2 \mathrm{~A})$. Western blot analysis of clinical samples also verified a significantly increased mRNA expression of Prx II in GC tissues (P<0.01; Fig. 2B). In addition, compared with poorly differentiated (Fig. 3B) and moderately differentiated GC tissues (Fig. 3C) the expression of Prx II in adjacent tissues was significantly downregulated (Fig. 3A). There was a little difference between the expression of Prx II in the highly differentiated GC tissues (Fig. 3D) and adjacent tissues. The positive expression rate of Prx II was $76.7 \%$ (89/116) in the GC tissues and 30.1\% (35/116) in the non-cancerous tissues $\left(\chi^{2}=50.516 ; \mathrm{P}<0.01\right)$.

Levels of Prx II expression predicts the survival of patients with $G C$. According to the results of immunohistochemistry, 116 GC patients were classified into two groups: High expression $(n=89)$ and low expression group $(n=27)$. As presented in Table I, Prx II protein expression was significantly associated with tumor size $(\mathrm{P}=0.029)$, histological differentiation $(\mathrm{P}=0.024)$, depth of invasion $(\mathrm{P}<0.001)$, TNM stage $(\mathrm{P}<0.001)$ and lymph node metastasis $(\mathrm{P}<0.001)$. No significant associations were identified between the expression of Prx II protein, and sex, age, location or distant metastasis $(\mathrm{P}>0.05)$. Kaplan-Meier analysis demonstrated that patients with low levels expression of Prx II had longer overall and disease-free survival times compared with those with high Prx II levels ( $\mathrm{P}<0.01$; Fig. 3E and F). Cox multivariate analysis revealed that Prx II, depth of invasion, lymph node metastasis and distant metastasis were independent predictors of overall survival in patients with GC $(\mathrm{P}<0.05$; Table II). Similar results were also obtained for disease-free survival in patients with GC $(\mathrm{P}<0.05$; Table III). Taken together, these clinical findings indicated that Prx II expression was an important indicator of survival for patients with GC among the analyzed factors.

Prx II knockdown suppresses GC cell proliferation. In order to investigate whether Prx II knockout affected the proliferation of GC cells, a CCK-8 assay was used performed. As presented in Fig. 4, the proliferation rate in positive control group (siRNA) was significantly suppressed at different times $(48,72$ and $96 \mathrm{~h})$, particularly at $96 \mathrm{~h}(\mathrm{P}<0.05)$. However, no significant differences were observed between the normal cultured group (blank) and the negative control group (NC) $(\mathrm{P}>0.05)$.

Prx II knockdown suppresses the expression of E-cadherin, $N$-cadherin, MMP-2 and MMP-9, and GC cell migration.
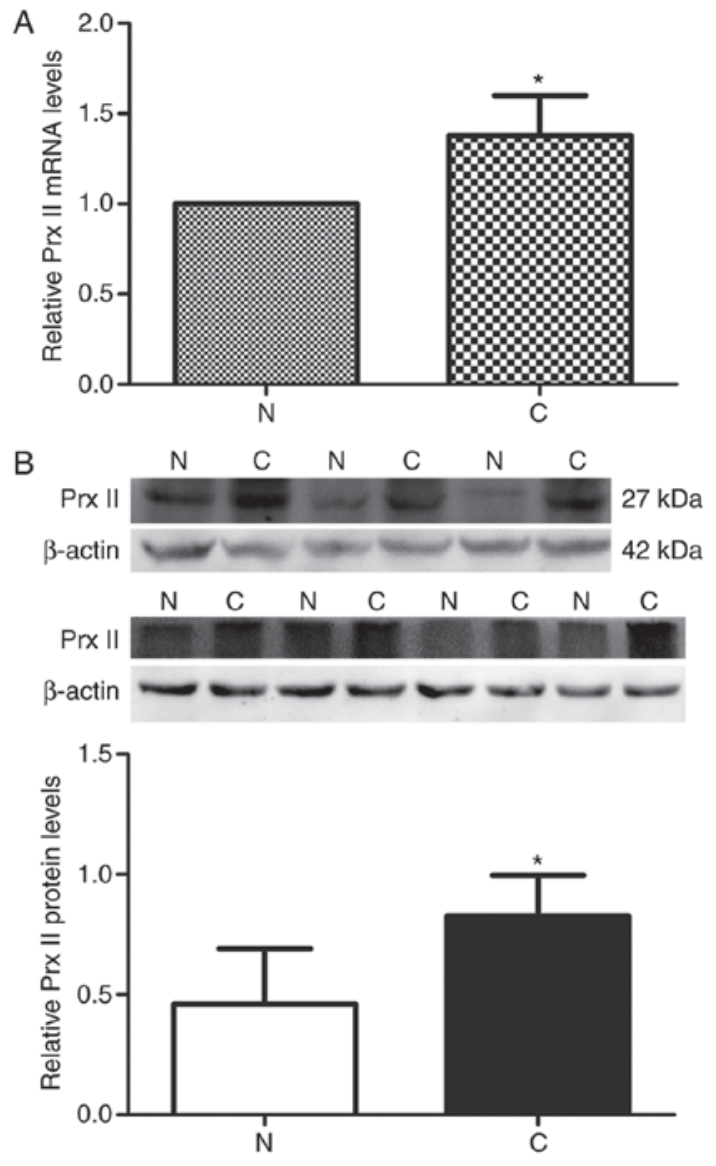

Figure 2. High levels of Prx II in GC tissues. (A) Reverse transcriptionquantitative polymerase chain reaction and (B) western blotting was used to determine the mRNA and protein expression of Prx II in GC tissues ( $n=45)$. The mRNA and protein levels of Prx II were analyzed in non-cancerous gastric tissues and GC tissues. Each bar represents three independent experiments presented as the mean \pm standard deviation; error bars represent the standard deviation. ${ }^{*} \mathrm{P}<0.05$ vs. N. Prx, peroxiredoxin; GC, gastric cancer; $\mathrm{N}$, non-cancerous; $\mathrm{C}$, cancerous.

As presented in Fig. 5, the western blot analysis revealed that silencing Prx II resulted in significantly decreased protein expression levels of MMP-2, MMP-9 and N-cadherin, and increased expression of E-cadherin in MGC-803 and MKN-45 cells compared with the $\mathrm{NC}$ group $(\mathrm{P}<0.05)$. The cell relocation measure showed that the transfection lessened the cell movement capacity by $53.7 \%$ for MGC- 803 and by $63.5 \%$ for MKN-45 cells compared with the control group (Fig. 6A; $\mathrm{P}<0.05$ ). Additionally, an invasion assay was used quantify the invasive capacity of the cells through channels covered with a reconstituted cellar membrane. It was demonstrated that the transfection significantly reduced the invasive capacity by $59.6 \%$ in MGC- 803 and by $54.8 \%$ in MKN-45 cells compared with the control group (Fig. 6B; $\mathrm{P}<0.05$ ).

\section{Discussion}

According to the cysteine residues present at the carboxyl and N-terminus, Prxs may be divided into three categories: 1-Cys Prx, typical 2-Cys Prx and atypical 2-Cys Prx. Prx II belongs to the typical 2-Cys Prx class $(22,23)$. Prx II is involved in regulating cell proliferation, differentiation, apoptosis and signaling pathways, and they serve antioxidative defense roles 
A

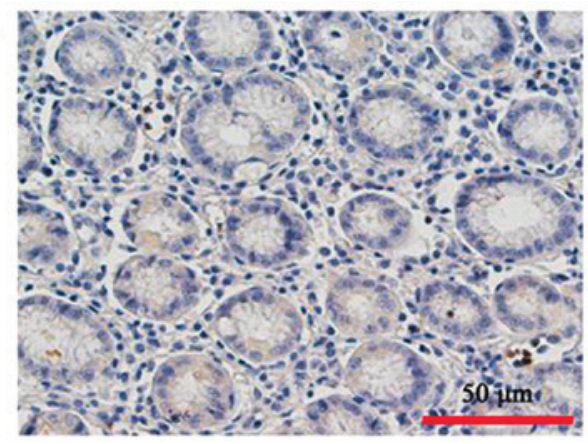

C

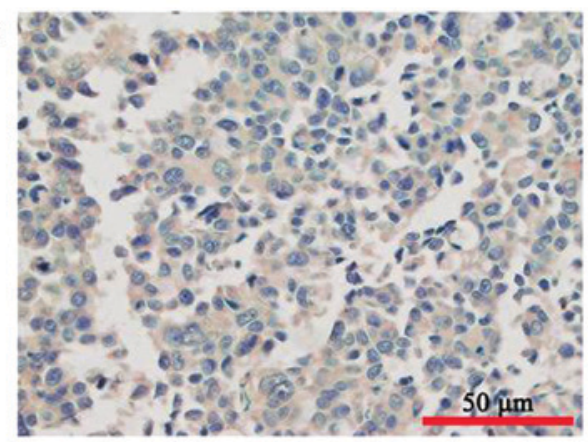

E

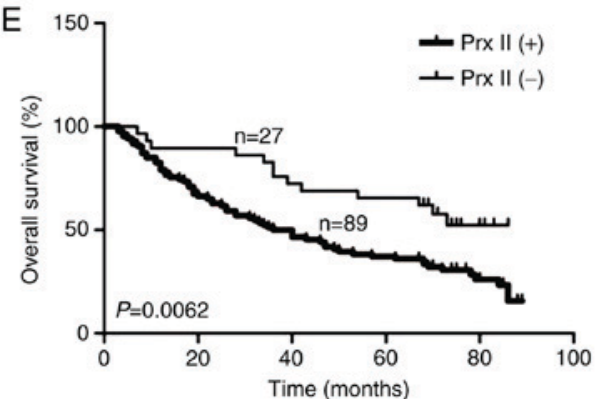

B

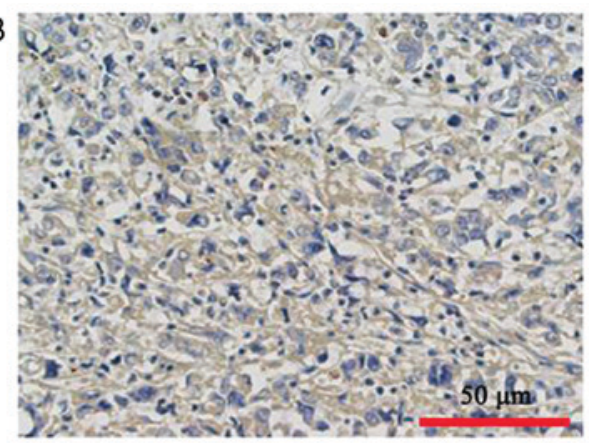

$\mathrm{D}$
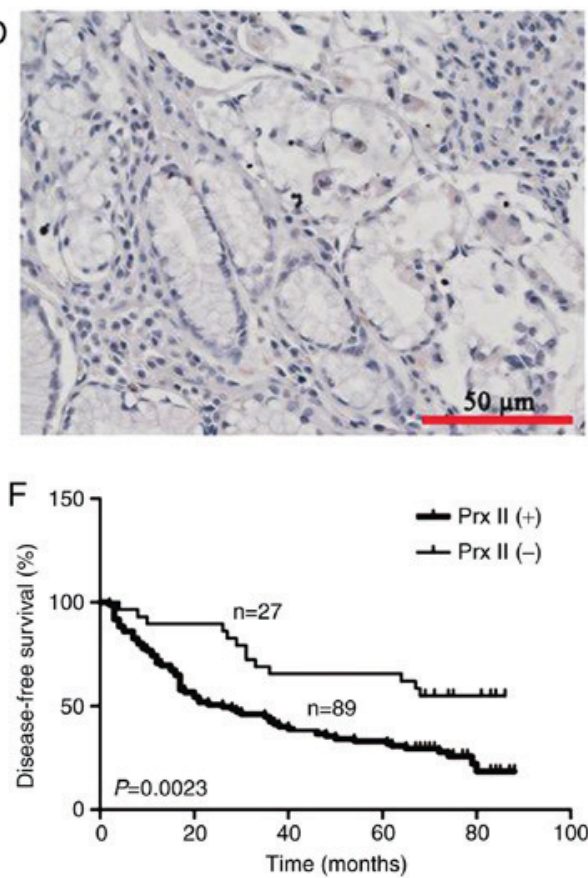

Figure 3. Prx II is upregulated in GC tissues and predicted a significantly lower overall and disease-free in patients with GC (n=116). Immunohistochemical staining for Prx II in (A) non-cancerous gastric tissues, (B) poorly differentiated GC tissues, (C) moderately differentiated GC tissues and (D) highly differentiated GC tissues. Prx II was expressed in poorly and moderately differentiated GC tissues, but it was negative in highly differentiated GC tissues and non-cancerous gastric tissues (magnification, x400). Kaplan-Meier (E) overall and (F) disease-free survival curves between Prx II high and low expression groups. Prx, peroxiredoxin; GC, gastric cancer.

by reducing and detoxifying various reactive oxygen species (ROS) that incorporate hydrogen peroxide $\left(\mathrm{H}_{2} \mathrm{O}_{2}\right)$. It has been demonstrated that high levels of Prx II reduce $\mathrm{H}_{2} \mathrm{O}_{2}$-induced apoptosis in thyroid cells (24). Kang et al (25) reported that the high expression of PrxII may participate in cell differentiation and apoptosis through inhibiting the production of NF- $\mathrm{NB}$. In addition, knockdown of Prx II prompts advance platelet-derived growth factor-induced cell division and metastasis (26). Recent studies have shown that PrxII participates in the activation of extracellular signal-regulated kinase (ERK), but that it does not participate in the activation of Janus kinase and p38 mitogen-activated protein kinase (MAPK). In fact, overexpression of PrxII in activated T cells increases the activation of the MAPK kinase (MEK)/ERK pathway induced by CD3 (27). In vascular endothelial cells, downregulation of PrxII can inhibit the activation of ERK (28).

According to previous studies, Prx II expression is increased in lung (15), renal (16), hepatocellular (29) and bosom carcinoma (30). GC is one of the most devastating types of tumor worldwide. In the present study, Prx II was upregulated in GC cell lines and GC tissues from patients, and high expression of Prx II was significantly associated with tumor size $(\mathrm{P}=0.029)$, histological differentiation $(\mathrm{P}=0.024)$, depth of invasion $(\mathrm{P}<0.001)$, TNM stage $(\mathrm{P}<0.001)$ and lymph node metastasis $(\mathrm{P}<0.001)$. Notably, Kaplan-Meier analysis revealed that patients with high Prx II expression had a poorer overall survival time $(\mathrm{P}=0.0062)$ and disease-free survival time $(\mathrm{P}=0.0023)$ compared with those with low Prx II. Cox multivariate analysis revealed that Prx II, depth of invasion, lymph node metastasis and distant metastasis were independent predictors of overall survival in patients with GC. Thus, thus this indicates that Prx II may aid in improving survival prediction of patients with GC.

It has been indicated that cells in a mild oxidation state do not cause the upregulation or downregulation of Prx II, while cells in a severe oxidation state promote the upregulation of Prx II (31). Thus, the antioxidation system serves an important role in regulating peroxide levels and changes to redox states (31). Therefore, high expression levels of Prx II may be associated with a state of persistent oxidation in the tumor tissue microenvironment. A chronic hypoxic state surrounds tumor tissues, and may induce apoptosis of carcinoma cells (32). Thus, the 
Table I. Association between the protein expression of Prx II and clinicopathological parameters in GC.

\begin{tabular}{|c|c|c|c|c|}
\hline \multirow[b]{2}{*}{ Variable } & \multirow[b]{2}{*}{ No. of patients } & \multicolumn{2}{|c|}{ Prx II (\%) } & \multirow[b]{2}{*}{ P-value } \\
\hline & & High & Low & \\
\hline \multicolumn{5}{|l|}{ Sex } \\
\hline Male & 78 & $60(76.9)$ & $18(23.1)$ & 0.942 \\
\hline Female & 38 & $29(76.3)$ & $9(23.7)$ & \\
\hline \multicolumn{5}{|l|}{ Age, years } \\
\hline$<59$ & 57 & $42(73.7)$ & $15(26.3)$ & 0.446 \\
\hline$\geq 59$ & 59 & $47(79.7)$ & $12(20.3)$ & \\
\hline \multicolumn{5}{|l|}{ Tumor size, $\mathrm{cm}$} \\
\hline$<5$ & 56 & $38(67.9)$ & $18(32.1)$ & 0.029 \\
\hline$\geq 5$ & 60 & $51(85)$ & $9(15)$ & \\
\hline \multicolumn{5}{|l|}{ Location } \\
\hline Other location & 45 & $31(68.9)$ & $14(31.1)$ & 0.115 \\
\hline Gastric antrum & 71 & $58(81.7)$ & $13(18.3)$ & \\
\hline \multicolumn{5}{|l|}{ Depth of invasion } \\
\hline $\mathrm{T} 1+\mathrm{T} 2$ & 21 & $4(19.0)$ & $17(81.0)$ & $<0.001$ \\
\hline $\mathrm{T} 3+\mathrm{T} 4$ & 95 & $85(90.4)$ & $10(9.6)$ & \\
\hline \multicolumn{5}{|l|}{ Differentiation } \\
\hline Poor & 69 & $58(84.1)$ & $11(15.9)$ & 0.024 \\
\hline Moderate/high & 47 & $31(66.0)$ & $16(34.0)$ & \\
\hline \multicolumn{5}{|l|}{ TNM stage } \\
\hline $\mathrm{I}+\mathrm{II}$ & 39 & $17(43.6)$ & $22(56.4)$ & $<0.001$ \\
\hline III & 77 & $72(93.5)$ & $5(6.5)$ & \\
\hline \multicolumn{5}{|l|}{ LNM } \\
\hline No & 33 & $14(43.6)$ & $19(56.4)$ & $<0.001$ \\
\hline Yes & 83 & $75(93.5)$ & $8(6.5)$ & \\
\hline \multicolumn{5}{|l|}{ Distant metastasis } \\
\hline No & 101 & $76(75.2)$ & $25(24.8)$ & 0.263 \\
\hline Yes & 15 & $13(86.7)$ & $2(13.3)$ & \\
\hline
\end{tabular}

LNM, lymph node metastasis; TNM, tumor node metastasis; Prx, peroxiredoxin; GC, gastric cancer.

Table II. Univariable and multivariable analysis of predictors of overall survival in patients with GC.

\begin{tabular}{|c|c|c|c|c|}
\hline \multirow[b]{2}{*}{ Variable } & \multirow{2}{*}{$\frac{\text { Univariable analysis }}{\text { HR }(95 \% \mathrm{CI})}$} & \multirow[b]{2}{*}{$\mathrm{P}$-value } & \multirow{2}{*}{$\frac{\text { Multivariable analysis }}{\operatorname{HR}(95 \% \mathrm{CI})}$} & \multirow[b]{2}{*}{ P-value } \\
\hline & & & & \\
\hline Prx II expression & $2.643(1.395-5.007)$ & 0.003 & $2.034(1.395-5.007)$ & 0.037 \\
\hline Sex & $0.952(0.593-1.530)$ & 0.839 & - & NA \\
\hline Age & $0.796(0.513-1.263)$ & 0.309 & - & NA \\
\hline Tumor size & $1.571(1.009-2.445)$ & 0.045 & $1.101(0.687-1.765)$ & 0.690 \\
\hline Location & $1.429(0.914-2.232)$ & 0.117 & - & NA \\
\hline Depth of invasion & $3.338(1.533-7.270)$ & 0.002 & $3.983(1.039-14.919)$ & 0.044 \\
\hline Differentiation & $0.652(0.409-1.038)$ & 0.031 & $0.894(0.554-1.443)$ & 0.119 \\
\hline TNM stage & $3.496(2.029-6.025)$ & $<0.001$ & $1.305(0.055-2.305)$ & 0.380 \\
\hline LNM & $0.196(0.103-0.373)$ & $<0.001$ & $0.106(0.032-0.351)$ & $<0.001$ \\
\hline Distant metastasis & $0.353(0.189-0.659)$ & 0.001 & $0.604(0.288-1.053)$ & 0.042 \\
\hline
\end{tabular}

$\mathrm{HR}=1$, no association between the variable and tumor recurrence. LNM, lymph node metastasis; TNM, tumor node metastasis; Prx, peroxiredoxin; GC, gastric cancer; 95\% CI, 95\% confidence interval; HR, hazard risk ratio; NA, not applicable. 
Table III. Univariable and multivariable analysis of predictors of disease-free survival in patients with GC.

\begin{tabular}{|c|c|c|c|c|}
\hline \multirow[b]{2}{*}{ Variable } & \multirow{2}{*}{$\frac{\text { Univariable analysis }}{\text { HR }(95 \% \mathrm{CI})}$} & \multirow[b]{2}{*}{ P-value } & \multirow{2}{*}{$\frac{\text { Multivariable analysis }}{\text { HR }(95 \% \mathrm{CI})}$} & \multirow[b]{2}{*}{$\mathrm{P}$-value } \\
\hline & & & & \\
\hline Prx II expression & $2.590(1.908-4.776)$ & 0.006 & $2.168(0.645-4.028)$ & 0.032 \\
\hline Sex & $0.963(0.600-1.547)$ & 0.454 & - & NA \\
\hline Age & $0.775(0.414-1.181)$ & 0.291 & - & NA \\
\hline Tumor size & $1.575(1.012-2.452)$ & 0.044 & $1.111(0.692-1.783)$ & 0.664 \\
\hline Location & $1.450(0.928-2.265)$ & 0.103 & - & NA \\
\hline Depth of invasion & $3.793(1.742-8.260)$ & $<0.001$ & $4.127(1.073-15.867)$ & 0.039 \\
\hline Differentiation & $0.669(0.171-2.244)$ & 0.040 & $0.839(0.288-2.125)$ & 0.143 \\
\hline TNM stage & $3.546(2.05-6.118)$ & $<0.001$ & $1.286(0.033-2.103)$ & 0.407 \\
\hline LNM & $0.190(0.100-0.363)$ & $<0.001$ & $0.095(0.028-0.321)$ & $<0.001$ \\
\hline Distant metastasis & $0.377(0.202-0.705)$ & 0.002 & $0.593(0.309-1.137)$ & 0.039 \\
\hline
\end{tabular}

$\mathrm{HR}=1$, no association between the variable and tumor recurrence. LNM, lymph node metastasis; TNM, tumor node metastasis; Prx, peroxiredoxin; GC, gastric cancer; 95\% CI, 95\% confidence interval; HR, hazard risk ratio; NA, not applicable.
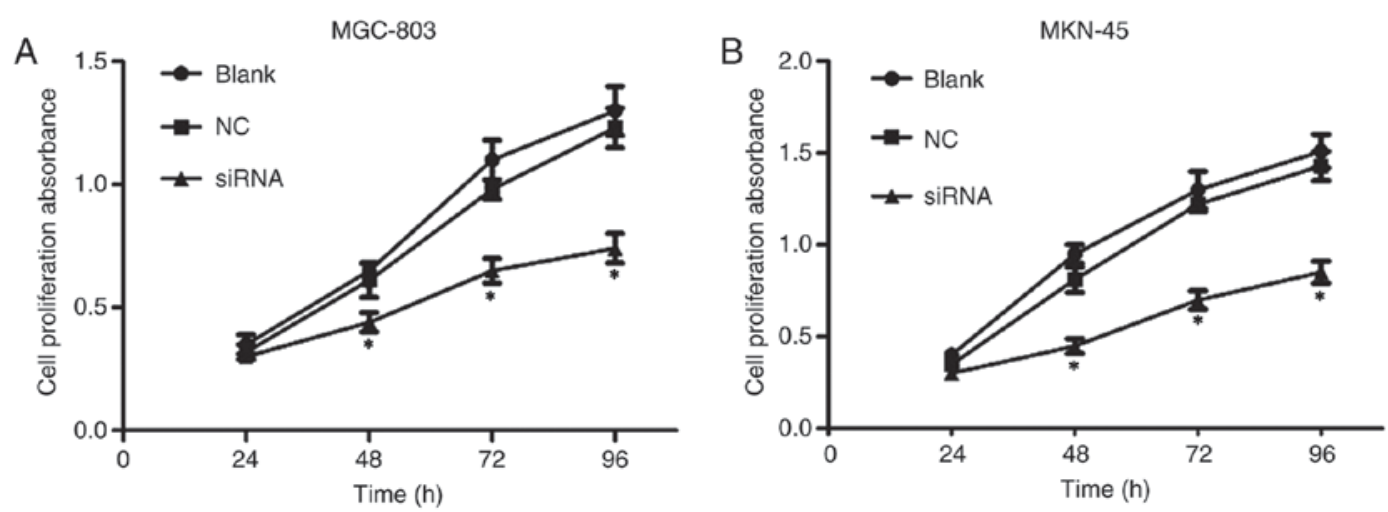

Figure 4. Prx II knockdown promotes gastric cancer cell proliferation. A cell counting assay was performed to examine the anti-proliferative effects of the transfection of siRNA in GC (A) MGC-803 and (B) MKN-45 cells. " $\mathrm{P}<0.05$ vs. Blank and NC. Prx, peroxiredoxin; NC, negative control; siRNA, small interfering RNA.

role of the antioxidation system of Prx II in the development of tumor cells is important. ROS includes organic hydroperoxide and $\mathrm{H}_{2} \mathrm{O}_{2}$. Increasing studies have demonstrated that ROS is associated with the development of cancer in the human body (33). Wang et al (34) reported that high Prx II levels are associated with the development of resistance of breast malignant cells to certain radiotherapies, and it may result in to reduced ROS levels. Thus, high Prx II expression levels may be associated with ROS.

Cell proliferation and migration are associated with various physiological processes. However, uncontrolled cell proliferation and migration may induce and progress tumor development (35). The present study used Transwell migration and invasion assays, and western blot analysis to detect the changes in invasion- and migration-associated genes. In the present study, it was demonstrated that Prx II knockdown significantly reduced the proliferation and migration rates of GC cells.

EMT-associated proteins, including E-cadherin and $\mathrm{N}$-cadherin, serve an important role in GC. EMT is associated with the metastasis of cancer, whereby epithelial cells become mesenchymal cells; however, EMT also typically occurs in tissue morphogenesis amid wound repair and tissue growth in healthy human tissues $(36,37)$. Altered expression levels of MMPs have been associated with the metastasis of numerous types of cancer. Degradation of the stromal cell layer is involved in the metastasis of cancer (38). MMP-2, along with MMP-9, is fit for debasing type IV collagen, which is the bottom of the stromal cell layer. Thus, tumor metastasis capacity is associated with E-cadherin, N-cadherin, MMP-2 and MMP-9. By utilizing western blot analysis, it was revealed that downregulating expression, the levels of MMP-2, MMP-9 and $\mathrm{N}$-cadherin protein were reduced, and that of E-cadherin was upregulated in GC cells. However, a limitation of the present study was that the activity levels of MMP-2 and -9 were not evaluated.

There have been various studies investigating the role of Prx II in the proliferation and metastasis of tumor. Lu et al (39) reported that downregulation of Prx II represses cell development in colorectal cancer by influencing the Wnt/ $\beta$-catenin signaling pathway. Park et al (29) demonstrated that Prx II increases hepatic tumorigenesis through collaboration with 

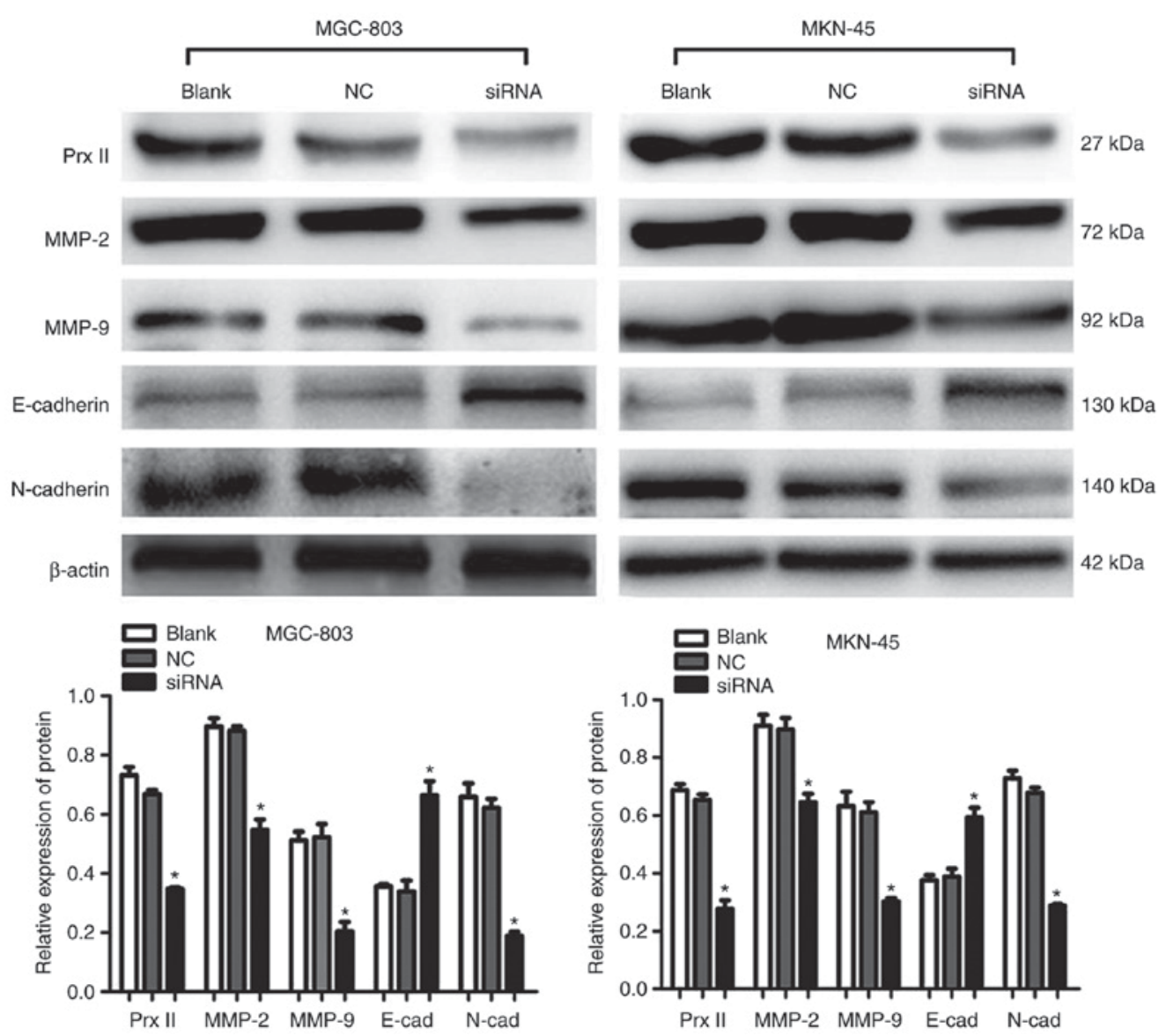

Figure 5. Interaction between Prx II, and E-cadherin, N-cadherin, MMP-2 and MMP-9 in gastric cancer MGC-803 and MKN-45 cells. The protein expression levels of Prx II, E-cadherin, N-cadherin, MMP-2 and MMP-9 were determined by western blot analysis. $\beta$-actin was used as a loading control. "P $<0.05$ vs. Blank and NC. Prx, peroxiredoxin; NC, negative control; siRNA, small interfering RNA; MMP, matrix metalloproteinase; E-cad, E-cadherin; N-cad, N-cadherin.

the Ras/Forkhead box M1 signaling pathway. Furthermore, certain studies have demonstrated that Prx II attenuates poly(ADP-ribose) polymerase 1-induced and p53-induced cell apoptosis Prx II transgenic mice (40). Low concentrations of ROS advance cell proliferation, whereas high concentrations of ROS advance cell apoptosis (41). Therefore, we hypothesized that Prx II may improve the limitation of tumor metastasis by regulating the level of ROS. As the present study was a preliminary study on the role of Prx II in the development and progression of GC, no further investigations into the role of ROS were performed. Therefore, it is a limitation of this study.

In conclusion, the current results reveal that Prx II is a necessary functional part of GC cell growth, but its molecular mechanism remains unclear. In addition, further in vitro and clinical studies on the effects of the Prx II gene in tumorigenesis are required. The results of the present study provide primary information and support the development of a novel treatment strategy in the management of GC.

\section{Acknowledgements}

The present study was supported by Jiangsu Key Laboratory of Biological Cancer Therapy. The authors would like to thank their colleagues at the Jiangsu Key Laboratory of Biological Cancer Therapy, Xuzhou Medical University for their technical assistance.

\section{Funding}

No funding was received.

\section{Availability of data and materials}

All data generated or analyzed during this study are included in this published article.

\section{Authors' contributions}

YG, LN, AL and WX were responsible for the design of the study. LN, AL, LY and WZ performed the experiments and collected the analytical data. $\mathrm{LN}$ and $\mathrm{AL}$ wrote the manuscript.

\section{Ethics approval and consent to participate}

Each patient was approved by the Ethics Review Board of the Affiliated Hospital of Xuzhou Medical College. All procedures performed in studies involving human participants were in accordance with the Declaration of Helsinki. Informed consent was obtained from all individual participants included in the study.

\section{Consent for publication}

Not applicable. 
A
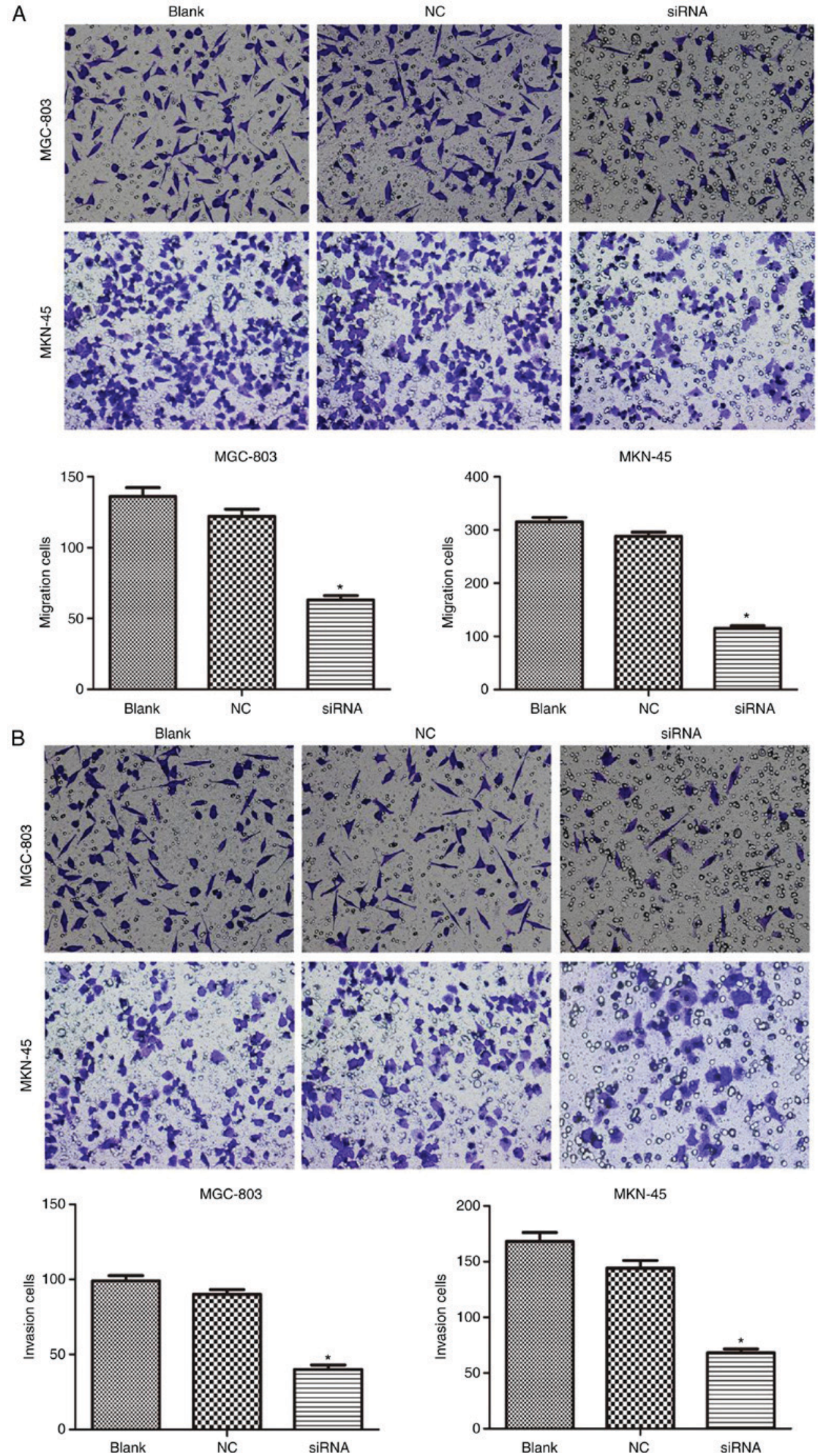

Figure 6. Prx II knockdown suppresses gastric cancer cells migration and invasion. (A) A cell migration assay was performed following Prx II knockdown in MGC-803 and MKN-45 cells. (B) Matrigel cell invasion abilities of MGC-803 and MKN-45 cells prior to and following transfection. Images of the cells that migrated onto the lower chamber of a Transwell plate were captured under a light microscope at x200 magnification. Each bar represents three independent experiments presented as the mean \pm standard deviation; error bars represent the standard deviation. ${ }^{*} \mathrm{P}<0.05$ vs. blank and siRNA. Prx, peroxiredoxin; NC, negative control; siRNA, small interfering RNA. 


\section{Competing interests}

The authors declare that they have no competing interests.

\section{References}

1. Jemal A, Bray F, Center MM, Ferlay J, Ward E and Forman D: Global cancer statistics. CA Cancer J Clin 61: 69-90, 2011.

2. Calcagno DQ, de Arruda Cardoso Smith M and Burbano RR: Cancer type-specific epigenetic changes: Gastric cancer. Methods Mol Biol 1238: 79-101, 2015.

3. Cheah IK, Lei F, Tang RMY, Lim KHC and Halliwell B: Ergothioneine levels in an elderly population decrease with age and incidence of cognitive decline; a risk factor for neurodegeneration? Biochem Biophys Res Commun 478: 162-167, 2016

4. Subramanya MS, Hossain MB, Khan S, Memon B and Memon MA: Meta-analysis of D1 versus D2 gastrectomy for gastric adenocarcinoma. In: Islamic Countries Conferecne on Statistical Sciences, 2009.

5. Conteduca V, Sansonno D, Lauletta G, Russi S, Ingravallo G and Dammacco F: H. pylori infection and gastric cancer: State of the art (review). Int J Oncol 42: 5-18, 2013.

6. Venerito M, Vasapolli R, Rokkas T, Delchier JC and Malfertheiner P: Helicobacter pylori, gastric cancer and other gastrointestinal malignancies. Helicobacter: 22 (Suppl 1), 2017.

7. Sarker KK, Kabir MJ, Bhuyian AKMMU, Alam MS, Chowdhury FR, Ahad MA, Rahman MA and Rahman MM: $\mathrm{H}$. pylori infection and gastric cancer in Bangladesh: A casecontrol study. Int J Surg Oncol (N Y) 2: e44, 2017.

8. Grabsch HI and Tan P: Gastric cancer pathology and underlying molecular mechanisms. Dig Surg 30: 150-158, 2013.

9. Canu V, Sacconi A, Lorenzon L, Biagioni F, Lo Sardo F, Diodoro MG, Muti P, Garofalo A, Strano S, D'Errico A, et al: MiR-204 down-regulation elicited perturbation of a gene target signature common to human cholangiocarcinoma and gastric cancer. Oncotarget 8: 29540-29557, 2017.

10. Abbas M, Habib M, Naveed M, Karthik K, Dhama K, Shi M and Dingding C: The relevance of gastric cancer biomarkers in prognosis and pre- and post-chemotherapy in clinical practice. Biomed Pharmacother 95: 1082-1090, 2017.

11. Gong F, Hou G, Liu H and Zhang M: Peroxiredoxin 1 promotes tumorigenesis through regulating the activity of mTOR/p70S6K pathway in esophageal squamous cell carcinoma. Med Oncol 32: $455,2015$.

12. Choi H, Chang JW and Jung YK: Peroxiredoxin 6 interferes with TRAIL-induced death-inducing signaling complex formation by binding to death effector domain caspase. Cell Death Differ 18 405-414, 2011

13. Perkins A, Poole LB and Karplus PA: Tuning of peroxiredoxin catalysis for various physiological roles. Biochemistry 53: 7693-7705, 2014

14. Nyström T, Yang J and Molin M: Peroxiredoxins, gerontogenes linking aging to genome instability and cancer. Genes Dev 26 2001-2008, 2012.

15. Lehtonen ST, Svensk AM, Soini Y, Pääkkö P, Hirvikoski P, Sang WK, Säily $M$ and Kinnula VL: Peroxiredoxins, a novel protein family in lung cancer. Int J Cancer 111: 514-521, 2004

16. Soini Y, Kallio JP, Hirvikoski P, Helin H, Kellokumpu-Lehtinen P, Kang SW, Tammela TL, Peltoniemi M, Martikainen PM and Kinnula VL: Oxidative/nitrosative stress and peroxiredoxin 2 are associated with grade and prognosis of human renal carcinoma. APMIS 114: 329-337, 2006

17. Wu Y and Zhou BP: Epithelial-Mesenchymal Transition in Development and Diseases. Springer New York, 2009.

18. Petrova YI, Schecterson L and Gumbiner BM: Roles for E-cadherin cell surface regulation in cancer. Mol Biol Cell 27: 3233-3244, 2016.

19. Xian X, Huang L, Zhang B, Wu C, Cui J and Wang Z: WIN 55,212-2 inhibits the epithelial mesenchymal transition of gastric cancer cells via COX-2 signals. Cell Physiol Biochem 39: 2149-2157, 2016

20. Lv Z, Weng X, Du C, Zhang C, Xiao H, Cai X, Ye S, Cheng J, Ding C, Xie H, et al: Downregulation of HDAC6 promotes angiogenesis in hepatocellular carcinoma cells and predicts poor prognosis in liver transplantation patients. Mol Carcinog 55 1024-1033, 2016
21. Livak KJ and Schmittgen TD: Analysis of relative gene expression data using real-time quantitative PCR and the 2(-Delta Delta C(T)) method. Methods 25: 402-408, 2001

22. Ow SH, Chua PJ and Bay BH: Epigenetic regulation of peroxiredoxins: Implications in the pathogenesis of cancer. Exp Biol Med (Maywood) 242: 140-147, 2017.

23. Rhee SG, Chae HZ and Kim K: Peroxiredoxins: A historical overview and speculative preview of novel mechanisms and emerging concepts in cell signaling. Free Radic Biol Med 38 $1543-1552,2005$

24. Kim H, Lee TH, Park ES, Suh JM, Park SJ, Chung HK, Kwon OY, Kim YK, Ro HK and Shong M: Role of peroxiredoxins in regulating intracellular hydrogen peroxide and hydrogen peroxide-induced apoptosis in thyroid cells. J Biol Chem 275 18266-18270, 2000.

25. Kang SW, Chae HZ, Seo MS, Kim K, Baines IC and Rhee SG: Mammalian peroxiredoxin isoforms can reduce hydrogen peroxide generated in response to growth factors and tumor necrosis factor-alpha. J Biol Chem 273: 6297-6302, 1998.

26. Choi MH, Lee IK, Kim GW, Kim BU, Han YH, Yu DY, Park HS, Kim KY, Lee JS, Choi C, et al: Regulation of PDGF signalling and vascular remodelling by peroxiredoxin II. Nature 435 347-353, 2005.

27. Kwon J, Devadas S and Williams MS: T cell receptor-stimulated generation of hydrogen peroxide inhibits MEK-ERK activation and lck serine phosphorylation. Free Radic Biol Med 35: 406-417, 2003

28. Kang DH, Lee DJ, Lee KW, Park YS, Lee JY, Lee SH, Koh YJ, Koh GY, Choi C, Yu DY, et al: Peroxiredoxin II Is an essential antioxidant enzyme that prevents the oxidative inactivation of VEGF receptor- 2 in vascular endothelial cells. Mol Cell 44 545-558, 2011.

29. Park YH, Kim SU, Kwon TH, Kim JM, Song IS, Shin HJ Lee BK, Bang DH, Lee SJ, Lee DS, et al: Peroxiredoxin II promotes hepatic tumorigenesis through cooperation with Ras Forkhead box M1 signaling pathway. Oncogene 35: 3503-3513, 2016.

30. Karihtala P, Mäntyniemi A, Kang SW, Kinnula VL and Soini Y Peroxiredoxins in breast carcinoma. Clin Cancer Res 9: 3418-3424, 2003

31. Lehtonen ST, Markkanen PM, Peltoniemi M, Kang SW and Kinnula VL: Variable overoxidation of peroxiredoxins in human lung cells in severe oxidative stress. Am J Physiol Lung Cell Mo Physiol 288: L997-L1001, 2005.

32. Huang WJ and Zou XY: Influence of cilazapril and taurine on apoptosis of chronic hypoxic lung tissue. Chin J Patho, 1999.

33. Marengo B, Nitti M, Furfaro AL, Colla R, Ciucis CD Marinari UM, Pronzato MA, Traverso N and Domenicotti C: Redox homeostasis and cellular antioxidant systems: crucial players in cancer growth and therapy. Oxid Med Cell Longev 2016: 6235641, 2016.

34. Wang T, Diaz AJ and Yen Y: The role of peroxiredoxin II in chemoresistance of breast cancer cells. Breast Cancer (Dove Med Press) 6: 73-80, 2014.

35. Ward E: Cancer statistics, 2010. Ca A Cancer J Clin 62: 10-29, 2012.

36. Kim H, Yoo SB, Sun P, Jin Y, Jheon S, Lee CT and Chung JH: Alteration of the E-Cadherin/ $\beta$-Catenin Complex Is an Independent Poor Prognostic Factor in Lung Adenocarcinoma. Korean J Pathol 47: 44-51, 2013.

37. Brabletz T, Hlubek F, Spaderna S, Schmalhofer O,Hiendlmeyer E, Jung A and Kirchner T: Invasion and metastasis in colorectal cancer: epithelial-mesenchymal transition, mesenchymalepithelial transition, stem cells and beta-catenin. Cells Tissues Organs 179: 56-65, 2005.

38. Mook OR, Frederiks WM and Van Noorden CJ: The role of gelatinases in colorectal cancer progression and metastasis. Biochim Biophys Acta 1705: 69-89, 2004

39. Lu W, Fu Z, Wang H, Feng J, Wei J and Guo J: Peroxiredoxin 2 knockdown by RNA interference inhibits the growth of colorecta cancer cells by downregulating Wnt/ $\beta$-catenin signaling. Cancer Lett 343: 190-199, 2014

40. Leak RK, Zhang L, Luo Y, Li P, Zhao H, Liu X, Ling F, Jia J, Chen J and Ji X: Peroxiredoxin 2 battles poly(ADP-ribose) polymerase 1 - and $\mathrm{p} 53$-dependent prodeath pathways after ischemic injury. Stroke 44: 1124-1134, 2013.

41. Liu SL, Shi DY, Pan XH and Shen ZH: Inhibition of proliferation and expression of $\mathrm{N}$-ras in hepatoma cells by antioxidation treatment. Sheng Wu Hua Xue Yu Sheng Wu Wu Li Xue Bao (Shanghai) 33: 463-466, 2001. 